\title{
Comparative Microbial Communities of Anode Associated Soils in Sediment Microbial Fuel Cells of Rice Field and Drainage Ditch Soils
}

\author{
Daniel Liu ${ }^{1}$, Jimmy Kuo ${ }^{2,3}$, Shuai-Hao Wang ${ }^{1}$, Kien Meng Puah ${ }^{4}$, Chorng-Horng Lin ${ }^{1 *}$ \\ ${ }^{1}$ Department of Bioresources, Da-Yeh University, 168 University Road, Dacun, Changhua 51591, Taiwan \\ ${ }^{2}$ Department of Planning and Research, National Museum of Marine Biology and Aquarium, Pingtung 94450, Taiwan \\ ${ }^{3}$ Graduate Institute of Marine Biology, National Dong Hwa University, Pingtung 94450, Taiwan \\ ${ }^{4}$ Department of Biomedical Sciences, Da-Yeh University, 168 University Road, Dacun, Changhua 51591, Taiwan
}

Received: 21 April 2021

Accepted: 17 June 2021

\begin{abstract}
In this study, the microbial community of the anode-associated soil in sediment microbial fuel cells (MFCs) was investigated. Sediments from the drainage ditch (D) and rice field (RF) were treated with or without autoclaving for single-chamber and mediator-free MFCs. Without sterilization, the voltage output reached a maximum of 124 and $120 \mathrm{mV}$ for the sediments from D and RF on days 30 and 56, respectively. By day 40, the voltage output of the MFCs with sterilization became positive and continued to increase. The microbial communities of the different sediments were clustered together, indicating that the voltage release correlated positively with the presence of soil microbes. Spearman rank correlation analysis showed that the genus Geobacter was positively correlated with Defluviicoccus, Desulfatiglans, Sulfurimonas, Synthrophobacter, Thiobacillus, and Thermodesulfovibrio and negatively correlated with Holophaga, Opitutus, Paludibacter, and Pseudomonas. The genera Geothrix showed the dominant changes in the sediments with sterilization. These results indicate that the sediment MFC device could change the microbial composition adapted to the anodic environment.
\end{abstract}

Keywords: sediment microbial fuel cell, 16S rDNA, microbial community, anode associated soils

\section{Introduction}

Microbial fuel cells (MFCs) are a new technology for electrical energy generation that uses microorganisms to oxidize organic matter to produce electrical energy $[1,2]$. MFCs can be combined with seabed sediment and wastewater treatment to grow microorganisms

*e-mail: clin@mail.dyu.edu.tw from organic matter supplied by sediments and wastewater to achieve the dual goals of bioremediation and energy production $[1,3,4]$. Suspicious electron transfer pathways in the anode could occur in the exoelectrogenic bacteria, for example, Shewanella putrefaciens IR-1, Geobacter metallireducens, and Geobacter sulfurreducens, supplying electrons to the anode through direct contact or with nanowires. However, when a complex mixture of bacteria is applied to MFC, electron transfer can be due to quorum sensing chemicals, minerals as mediators, or cell-cell 
communication. For example, the oxidation of methane by anaerobic metanotrophic archaea is associated with sulfate reduction by sulfate-reducing bacteria $[5,6]$.

The content of the microbial community is influenced by environmental conditions and organic wastes. Previous studies have shown that there is a positive relationship between the microbial community and the output of the MFC. The Geobacteraceae harvested from marine sediment on the anode could improve the electricity generation [4]. Bacterial community and capacity analysis of sediment MFCs collected from marine sludge, saline and freshwater wetlands showed that Deltaproteobacteria were significantly increased on the anode, especially Geobacteraceae and Desulfobulbaceae, which were positively correlated with power generation efficiency [7]. Geobacter psychrophilus and its related species preferentially grow on the anodes of rice paddy-field MFCs and could generate electricity through syntrophic interactions with organisms that excrete electron donors [8]. Furthermore, this symbiotic relationship suggests that Sporomusa converts methanol to acetic acid, which is used by Geobacter to generate electricity [9]. The anodic biofilm community could also change in response to different nutrients, and the relative abundance of Geobacter followed the power density [10]. The surface potential and carbon sources also would affect the microbial communities [11]. Therefore, different sediments with diverse microbial and trophic conditions may affect the performance of MFCs and the adaptability of microorganisms.

This study aims to investigate the microbial communities and electricity outputs affected by different soil sources. We applied sediments from RF and D with and without autoclaving in single-chamber and mediator-free sediment MFCs for microbial community analyses. The voltages were recorded and $16 \mathrm{~S}$ rDNA was sequenced on the Illumina MiSeq platform. Microbial phylogeny and correlations were further analyzed using the MetaGenome Analyzer (MEGAN) and the $\mathrm{R}$ project.

\section{Materials and Methods}

\section{Sediment MFCs Construction and Operation}

The soils used in this study was collected from the rice field (RF) and the drainage ditch (D) $\left(24^{\circ} 00^{\prime} \mathrm{N}\right.$, 120'34'E) in Dacun Township, Changhua County, Taiwan (Fig. 1) and was divided into two groups with one hour sterilization by autoclave or no sterilization.

The single-chamber, mediator free sediment MFC devices were applied. The soil was placed in a transparent plastic container $(23 \times 14 \times 12 \mathrm{~cm})$ with $5 \mathrm{~cm}$ depth, and carbon fiber cloth $(11 \times 8 \mathrm{~cm}$, skyline carbon co. Taipei, Taiwan) was buried in the sediment soil as an anode (-), and a carbon rod $(8 \mathrm{~cm}$ in length, $0.5 \mathrm{~cm}$ in diameter) was attached to the wall under the buffer solution as the cathode $(+)$. The phosphate buffer solution of $\mathrm{pH} 7.2$ contains $0.137 \mathrm{M} \mathrm{NaCl}, 0.0027 \mathrm{M} \mathrm{KCl}$, $0.01 \mathrm{M} \mathrm{Na}_{2} \mathrm{HPO}_{4}$ and $0.0018 \mathrm{M} \mathrm{KH}_{2} \mathrm{PO}_{4}$.

The voltage and current were recorded on a dualchannel data collection multi-meter, Prova 803 (TES Electrical Electronic Crop. Taipei, Taiwan), and the data was downloaded by RS-232 interface connection to the computer. The performance of the MFCs, corresponding to changes in voltage and current, is analyzed by the following sequences of resistances: $22 \mathrm{M} \Omega, 1 \mathrm{M} \Omega$, $50 \mathrm{~K} \Omega, 10 \mathrm{~K} \Omega, 1 \mathrm{~K} \Omega, 680 \Omega, 300 \Omega, 150 \Omega, 5.1 \Omega$.

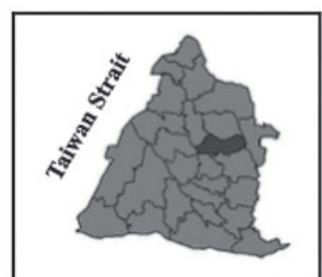

Changhua County

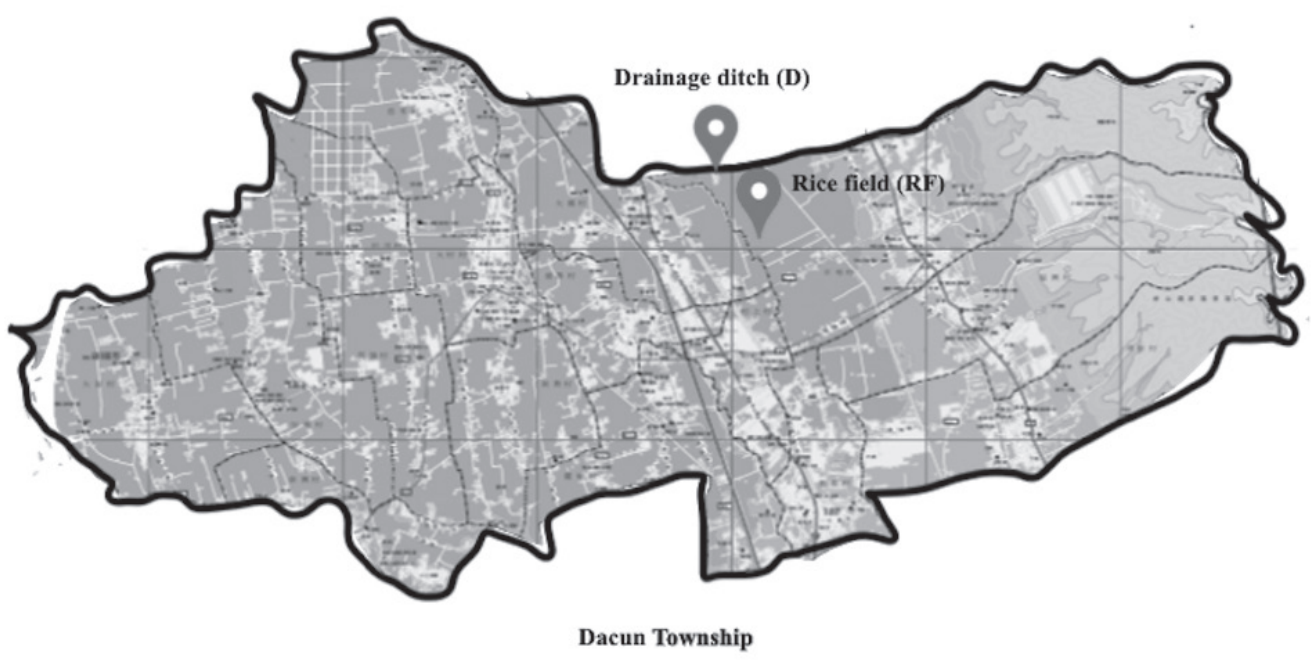

Fig. 1. Location and overview map of the researched area. 


\section{DNA Extraction, Polymerization Chain Reaction} (PCR) and Sequencing

Bacterial genomic DNA was extracted from $0.5 \mathrm{~g}$ of soil by using UltraClean soil DNA isolation kit (MO BIO Laboratory, Carlsbad, CA, USA), according to the manufacturer's instruction. V3 region of $16 \mathrm{~S}$ rRNA gene was amplified. Sequencing libraries were generated and sequenced on an Illumina MiSeq platform (Illumina, Inc., San Diego, CA). Nucleotide sequences determined in the study have been deposited into the MG-RAST server and the project IDs are mgm4898542.3, mgm4898543.3, mgm4898544.3, and mgm4898545.3 for samples D, DA, RF, and RFA respectively.

\section{Sequence Analyses}

Sequence analyses were first compared nucleotides to sequence databases by BLAST (Basic Local Alignment Search Tool) [12], and imported to MEGAN (MEtaGenome Analyzer) [13] for microbial communities, Shannon index, Simpson index, UPGMA (unweighted pair group method with arithmetic mean) cluster analyses. Heatmap of dominant genera was generated in $\mathrm{R}$ version 3.4.1 with the ComplexHeatmap function. Hierarchical clustering was conducted using spearman $[14,15]$. Spearman correlation of dominant genera was generated in $\mathrm{R}$ version 3.4.1 with the recorr and corrplot functions [15].

\section{Results and Discussion}

\section{Electricity Generation}

The results of daily voltage fluctuations showed that under the condition of $1 \mathrm{~K} \Omega$ external resistor as load, the output voltage of D sediment MFCs and RF sediment MFCs increased with time without sterilization treatment (Fig. 2). The D sediment MFC reached a maximum voltage of $124 \mathrm{mV}$ on day 30 , and
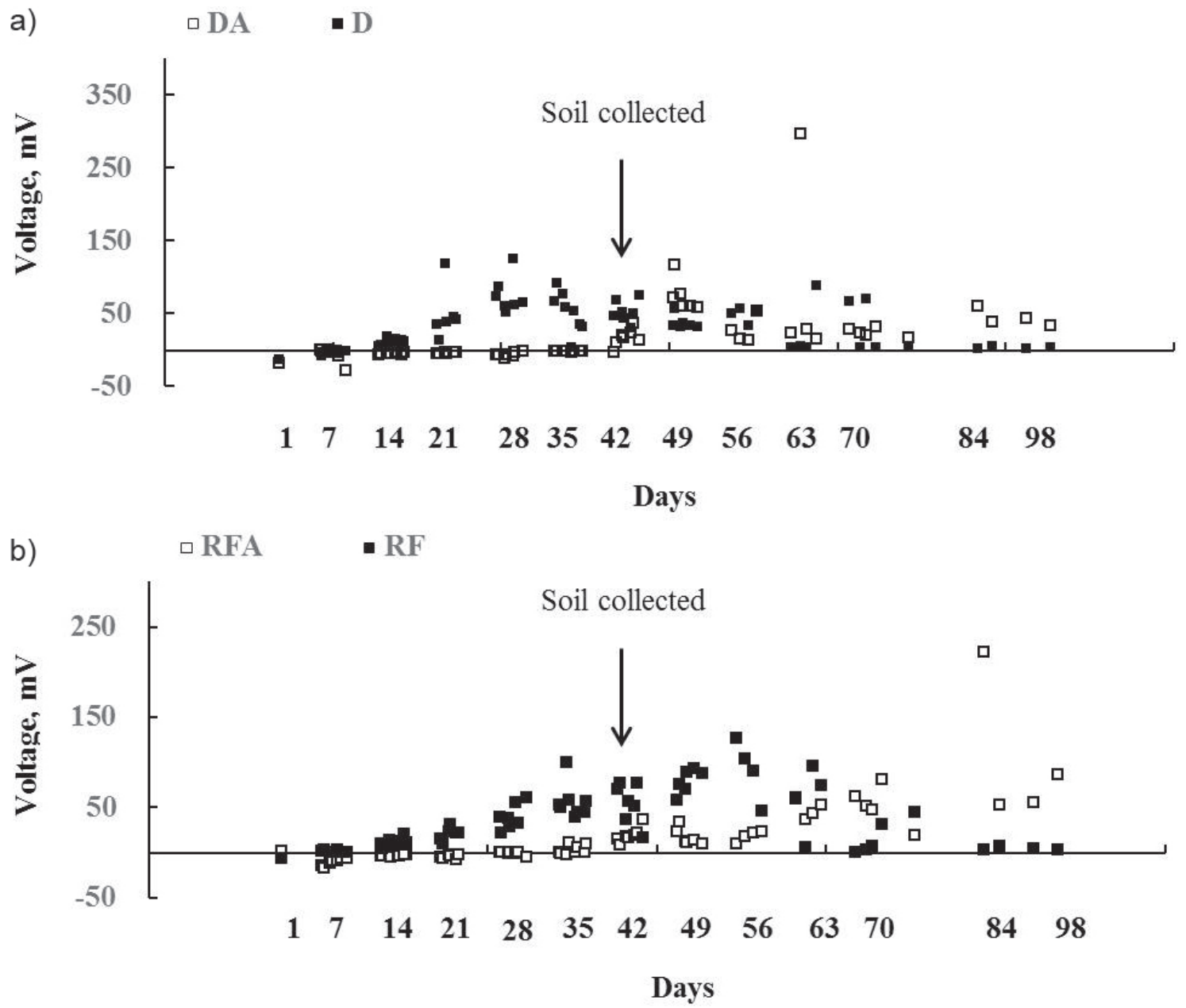

Fig. 2. a) The voltage fluctuation of the drainage ditch sediment NFC as a function of time. b) The voltage fluctuation of the rice field sediment MFC as a function of time. D and RF represent soils from the drainage ditch and rice field sediment. A indicates the soil was treated with sterilization. Solid square represents the soil treated without sterilization. Open square represents the soil treated with sterilization. The soil samples were collected on day 43 for the bacterial DNA preparation, and the overall genome analysis of $16 \mathrm{~S}$ rDNA sequencing. The voltages of D, DA, RF, and RFA sediment MFC were 49, 37, 76, $22 \mathrm{mV}$, respectively. 
the subsequent voltage output gradually decreased, and the RF-sediment MFC reached a maximum of $120 \mathrm{mV}$ on day 56. Analysis of the polarization curve on day 18 showed that the maximum power densities of the D and RF sediment MFCs without sterilization treatment were $0.1 \mathrm{mWm}^{-2}$ and $0.4 \mathrm{mWm}^{-2}$, with an external resistance of $50 \mathrm{~K} \Omega$ and $10 \mathrm{~K} \Omega$, respectively (Fig. S1). The voltage output for sterilized sediment MFCs was initially negative. As the number of days increased, the voltage value also increased. After the 40th day, the voltage output reached a positive value and continued to increase. On the $98^{\text {th }}$ day after the end of the experiment, the voltage output was higher than that of the non-sterilized sediment MFCs. The results showed that most of the microorganisms died after sterilization, resulting in a low initial voltage output, then the surviving microorganisms continued to grow and adapt to form anodic microbial communities.

\section{Phylogenetic Analyses of Anode-Associated Soil Microorganisms}

Fig. 3 compares the four sediment MFCs by percent composition of the different bacterial species. Without sterilization, the predominant microorganisms in the D MFC were Proteobacteria (53.6\%), Bacteroidetes (16\%), Firmicutes (7.5\%), Chloroflexi $(5.2 \%)$, and Verrucomicrobia (3.2\%), whereas in the
RF MFC, Proteobacteria (47.7\%), Bacteroidetes (19.2\%), Chloroflexi (5.6\%), Firmicutes (4.6\%), and Verrucomicrobia (4.1\%) were predominant. In sterilized sediments (DA and RFA), Proteobacteria (47.7\%), Bacteroidetes (17.5\%), Firmicutes (13.7\%), Euryarchaeota (4.7\%), and Verrucomicrobia (4.3\%) were the predominant microorganisms in DA MFC, whereas in the RFA MFC were Bacteroidetes (65.4\%), Proteobacteria (20.1\%), Firmicutes (6.9\%), Acidobacteria (1.4\%), and Verrucomicrobia (1.1\%). After sterilization, Bacteroidetes showed the most massive increase, and Chloroflexi showed the decrease. The change could be due to the growth rate in relation to the current production. Recent research has reported Proteobacteria (25-30\%), Chloroflexi (20\%), Acidobacteria (15\%), and Actinobacteria (10\%) were the predominant bacteria in rice fields soil [16]. Studies on the metagenomics of anode-associated microbiomes in rice paddy field MFCs suggested that the five predominant bacteria in anode-associated soil were Proteobacteria (49.2\%), Actinobacteria (2.5\%), Bacteroidetes (2.1\%), Chloroflexi (1.0\%), and Firmicutes $(0.8 \%)$ [8]. Our phylum level classification result was similar to the researches mentioned above. The possible explanations are that the similar natural environment was applied, and those significant predominant microorganisms might be influenced by the MFCs, but still in the larger portions.

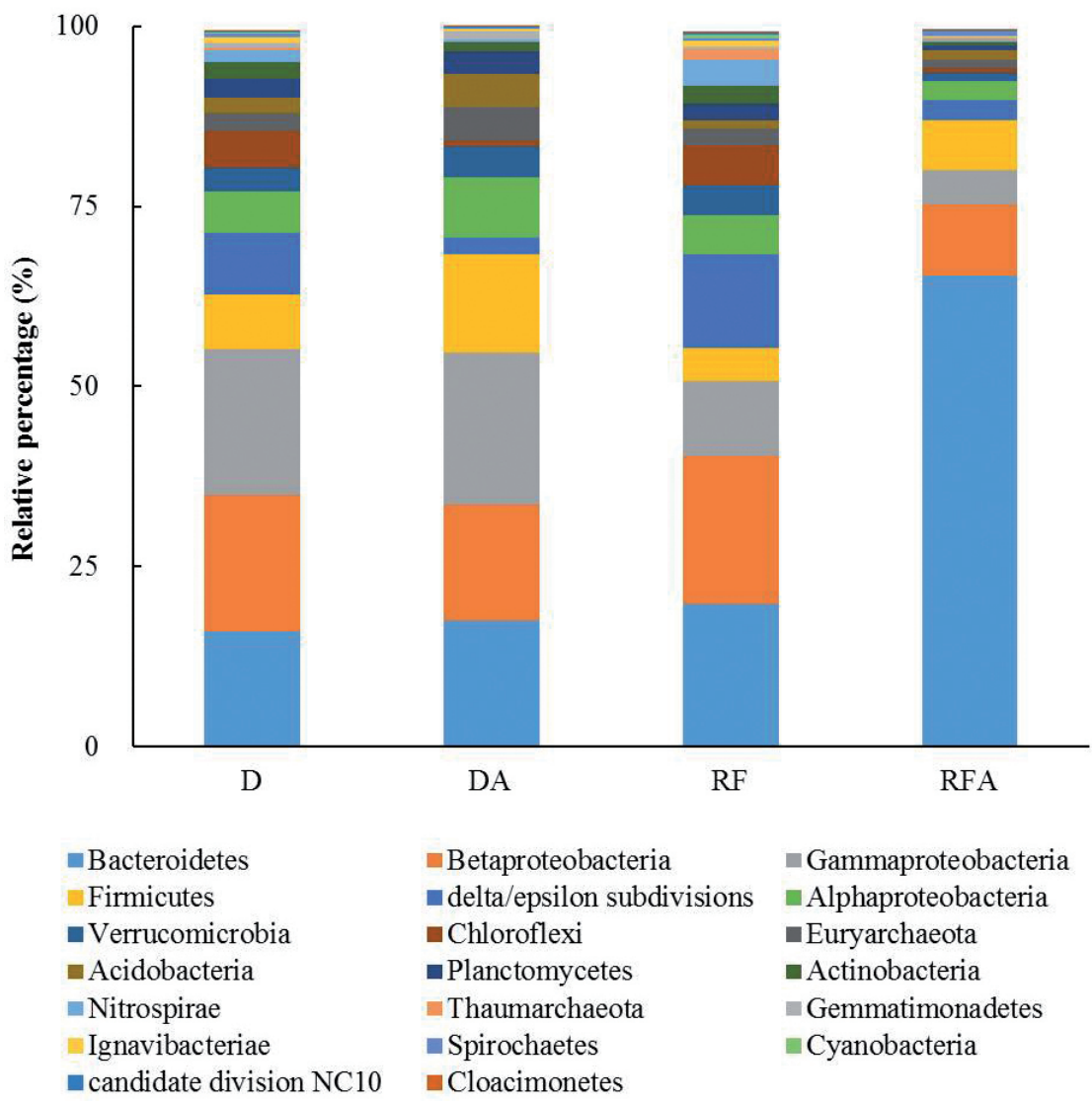

Fig. 3. The relative abundance of phyla of the microbial communities in sediment microbial fuel cells. 
a) $\longmapsto 0.01$

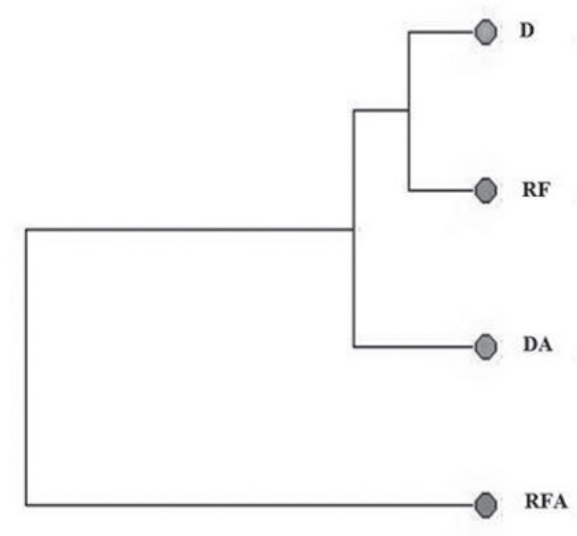

b) $\longmapsto 0.01$

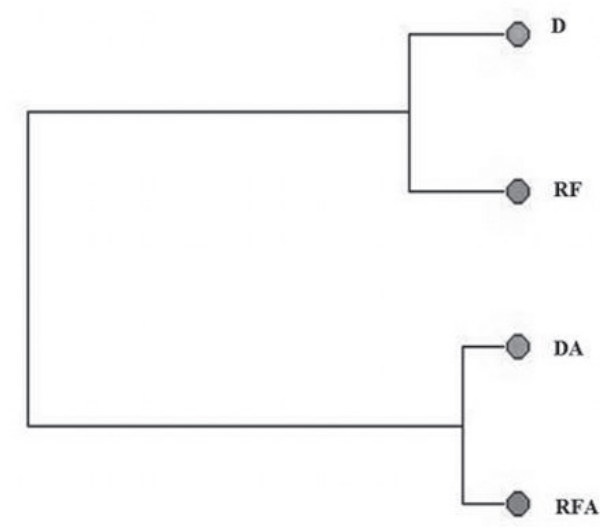

Fig. 4. UPGMA cluster analysis of soil microbial community in sediment microbial fuel cells. a) The tree was constructed with weighted uniform Unifrac metric. b) The tree was constructed with unweighted uniform Unifrac metric.

UPGMA dendrogram of soil microbial community in sediment MFCs showed a clear difference between the microbial communities with and without sterilization (Fig. 4). The energy output circuit may have actually contributed to the acclimation of certain microorganisms [8, 10, 17-19]. Most microorganisms died after sterilization. The microbial communities need time to reform and could evolve in a different direction.. Shannon and Simpson diversity index of soil microbial community showed the diversity decreased with sterilization (Table 1), which is probably the cause of the lower energy yield compared to the MFCs without sediment sterilization.

\section{Heatmap Clustering and Correlation Analyses of Anode-Associated Soil Microorganisms}

The heat map and clustering analysis used the microbial genera and quantities for graphical representation of clustering (Fig. 5). The result showed that the microbial communities in D and RF sediments were clustered together, indicating that the microbial communities were relative to a higher power output. Thus, the large number of microbes present in the $\mathrm{D}$ and RF sediments was the likely candidate for the exoelectrogens when they were relatively fewer in the DA and RFA sediments. We listed the twenty most dominant genera of microbial communities (Table 2), checking with the heatmap result (Fig. 5), revealed that Geobacter showed the dominant presence and contrasting distribution between unsterilized and sterilized sediments. To determine which microbes were responsible for the electricity generation in sterilized sediments, we studied the twenty most diverse species of bacterial communities in sterilized sediments compared to unsterilized sediments (DA/D and RFA/RF, Table 3). Geothrix and Paludibacter showed the dominant changes in both DA and RFA sediments. Although Paludibacter was detected as the dominant species in anodic biofilm, it did not correlate with power output [20,21]. It is likely that Paludibacter did not show the contrast but was abundant in four sediments (Fig. 5, Table 3). Geothrix fermentans, a Fe(III)-reducing bacterium, has been reported to be involved in the electron shuttle of electricity generation [22], and the Geothrix from rice paddy fields correlated with power [8], and were abundantly detected in anode biofilms [23]. Unfortunately, based on the methods used, we could not confirm that Geobacter and Geothrix were the major exoelectrogens in the MFCs. However, the change in quantity matched well with the voltage output. We further investigated the possible interaction for Geobacter and Geothrix with other microorganisms by Spearman rank correlation analysis.

Correlation results $(\mathrm{P}<0.01)$ suggested that Geobacter positively correlated with Desulfatiglans, Defluviicoccus, Thermodesulfovibrio, Thiobacillus, Sulfurimonas, and Syntrophobacter, and negatively with Holophaga, Opitutus, Paludibacter, and Pseudomonas; Geothrix correlated negatively with Anaerolinea,

Table 1. Shannon and Simpson diversity index of soil microbial community in sediment microbial fuel cells.

\begin{tabular}{|c|c|c|c|c|}
\hline & D & DA & RF & RFA \\
\hline Shannon-Weaver index & 5.846 & 4.460 & 6.229 & 3.711 \\
\hline Simpson's reciprocal index & 26.017 & 10.082 & 44.247 & 5.846 \\
\hline
\end{tabular}


Table 2 . The twenty most dominant genera of microbial community.

\begin{tabular}{|c|c|c|c|c|c|c|c|}
\hline \multicolumn{2}{|l|}{$\mathrm{D}$} & \multicolumn{2}{|l|}{ DA } & \multicolumn{2}{|l|}{ RF } & \multicolumn{2}{|l|}{ RFA } \\
\hline Genus & $\%$ & Genus & $\%$ & Genus & $\%$ & Genus & $\%$ \\
\hline Methylococcus & 9.93 & Paludibacter & 13.80 & Thiobacillus & 18.04 & Petrimonas & 24.00 \\
\hline Cupriavidus & 7.66 & Clostridium & 12.90 & Methylococcus & 3.91 & Echinicola & 19.82 \\
\hline Thiobacillus & 5.84 & Pusillimonas & 8.76 & Geobacter & 3.89 & Paludibacter & 10.41 \\
\hline Clostridium & 4.09 & Pseudomonas & 8.44 & Prosthecobacter & 3.28 & Thiobacillus & 3.48 \\
\hline Geobacter & 3.47 & Methanosarcina & 4.51 & Thermodesulfovibrio & 2.63 & Persicitalea & 2.70 \\
\hline Prosthecobacter & 2.91 & Prosthecobacter & 4.12 & Echinicola & 2.53 & Pseudomonas & 2.58 \\
\hline Flexibacter & 2.84 & Roseomonas & 3.33 & Desulfatiglans & 2.37 & Alkaliflexus & 2.37 \\
\hline Roseomonas & 2.28 & Isosphaera & 2.91 & Chitinophaga & 2.32 & Tolumonas & 2.20 \\
\hline Pseudomonas & 1.95 & Holophaga & 2.46 & Roseomonas & 1.99 & Proteocatella & 2.00 \\
\hline Flavobacterium & 1.83 & Stella & 2.17 & Alcaligenes & 1.84 & Nitrosomonas & 1.98 \\
\hline Leptolinea & 1.69 & Geothrix & 1.99 & Nitrosomonas & 1.71 & Clostridium & 1.89 \\
\hline Candidatus Solibacter & 1.64 & Thiobacillus & 1.91 & Pseudomonas & 1.67 & Roseivirga & 1.77 \\
\hline Paludibacter & 1.64 & Solitalea & 1.72 & Leptolinea & 1.64 & Cupriavidus & 1.76 \\
\hline Anaeromyxobacter & 1.55 & Candidatus Solibacter & 1.57 & Paludibacter & 1.43 & Barnesiella & 1.45 \\
\hline Anaerolinea & 1.42 & Parasegetibacter & 1.53 & Defluviicoccus & 1.36 & Roseomonas & 0.99 \\
\hline Parasegetibacter & 1.42 & Gemmatimonas & 1.42 & Clostridium & 1.33 & Geothrix & 0.96 \\
\hline Terrimonas & 1.33 & Kaistia & 1.35 & Terrimonas & 1.30 & Olivibacter & 0.88 \\
\hline Nitrospira & 1.29 & Dyadobacter & 1.30 & Flavobacterium & 1.28 & Geobacter & 0.79 \\
\hline Ruminiclostridium & 1.26 & Chitinophaga & 1.18 & Bellilinea & 1.27 & Prosthecobacter & 0.75 \\
\hline Chitinophaga & 1.17 & Opitutus & 1.15 & Sulfurimonas & 1.25 & Sulfurospirillum & 0.59 \\
\hline
\end{tabular}

Table 3. The twenty most difference genera of the microbial community in sediment with sterilization relative to the sediment without sterilization.

\begin{tabular}{|c|c|c|c|}
\hline Genus & DA/D fold & Genus & 27.26 \\
\hline Isosphaera & 24.32 & Alkaliflexus & 17.04 \\
\hline Holophaga & 9.02 & Barnesiella & 11.53 \\
\hline Geothrix & 8.60 & Sulfurospirillum & 11.44 \\
\hline Paludibacter & 8.44 & Candidatus Cloacimonas & 9.41 \\
\hline Desulfosporosinus & 8.24 & Methanospirillum & 7.83 \\
\hline Dehalobacter & 7.60 & Echinicola & 7.30 \\
\hline Ethanoligenens & 6.36 & Paludibacter & 6.69 \\
\hline Opitutus & 5.99 & Persicitalea & 6.66 \\
\hline Dyadobacter & 5.80 & Proteocatella & 6.59 \\
\hline Methanosarcina & 4.67 & Roseivirga & 5.37 \\
\hline Methanoregula & 4.56 & Parabacteroides & 4.21 \\
\hline Pseudomonas & 4.33 & Ruminiclostridium & 4.09 \\
\hline Sporomusa & 4.20 & Geothrix & 3.76 \\
\hline Methylarcula & 4.19 & Phenylobacterium & \\
\hline Kaistia & 4.11 & & \\
\hline
\end{tabular}


Table 3. Continued.

\begin{tabular}{|c|c|c|c|}
\hline Desulfitobacterium & 3.91 & Sporomusa & 3.45 \\
\hline Echinicola & 3.72 & Magnetospirillum & 3.26 \\
\hline Stella & 3.57 & Spirochaeta & 2.94 \\
\hline Solitalea & 3.23 & Treponema & 2.65 \\
\hline Acinetobacter & 3.16 & Methanoregula & \\
\hline
\end{tabular}

Flexibacter, Methylococcus, and Thiocystis (Fig. 6). Desulfatiglans [24], Thermodesulfovibrio, and Syntrophobacter [25] are sulfate-reducing bacteria (SRB), and SRB could cooperate with iron-reducing bacteria, Geobacter and Geothrix in iron, sulfur, and methane metabolic cycles [26, 27]. Sulfurimonas known as the sulfur oxidizing bacteria would anaerobically oxidize sulfur with nitrate as the electron acceptor [28] and could be involved in sulfur, nitrate, iron, and methane metabolic pathways [29]. Metagenomic analysis suggested Candidatus Defluviicoccus seviourii, a glycogen accumulating organism, would store polyhydroxyalkanoates and adapt to low nutrient conditions [30]. Thiobacillus, Desulfuromonas and Geobacter were identified as the main members of $\mathrm{Fe}$ (III)-reducing bacteria in the sediments of a heavily polluted freshwater lake [31]. Syntrophobacter was found to be involved in syntrophic oxidation of propionate in rice field soil, and Geobacter would also assimilate propionate [32]. Opitutus is an obligately anaerobic bacterium that ferments saccharides to produce propionate and acetate, and reduce nitrate

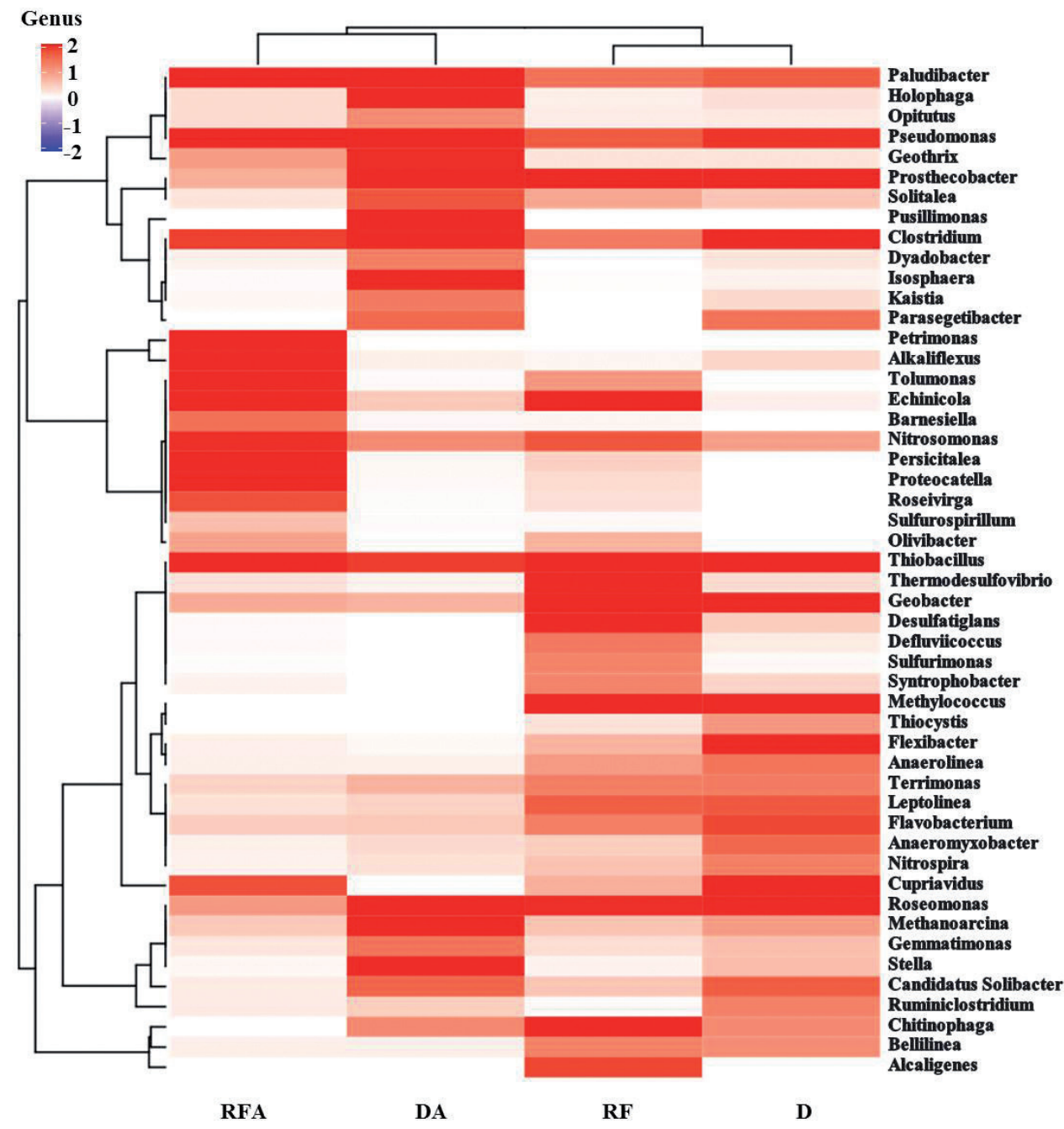

Fig. 5. Heatmap of dominant genera. The abundance distribution of the dominant 50 genera was displayed in the abundance heatmap. The colors of the scale bar represent the ' $z$ ' score. The absolute value of ' $z$ ' represents the spearman correlation distance between the raw score and the standard deviation mean population. ' $Z$ ' is negative when the raw score is below the mean, and vice versa. 


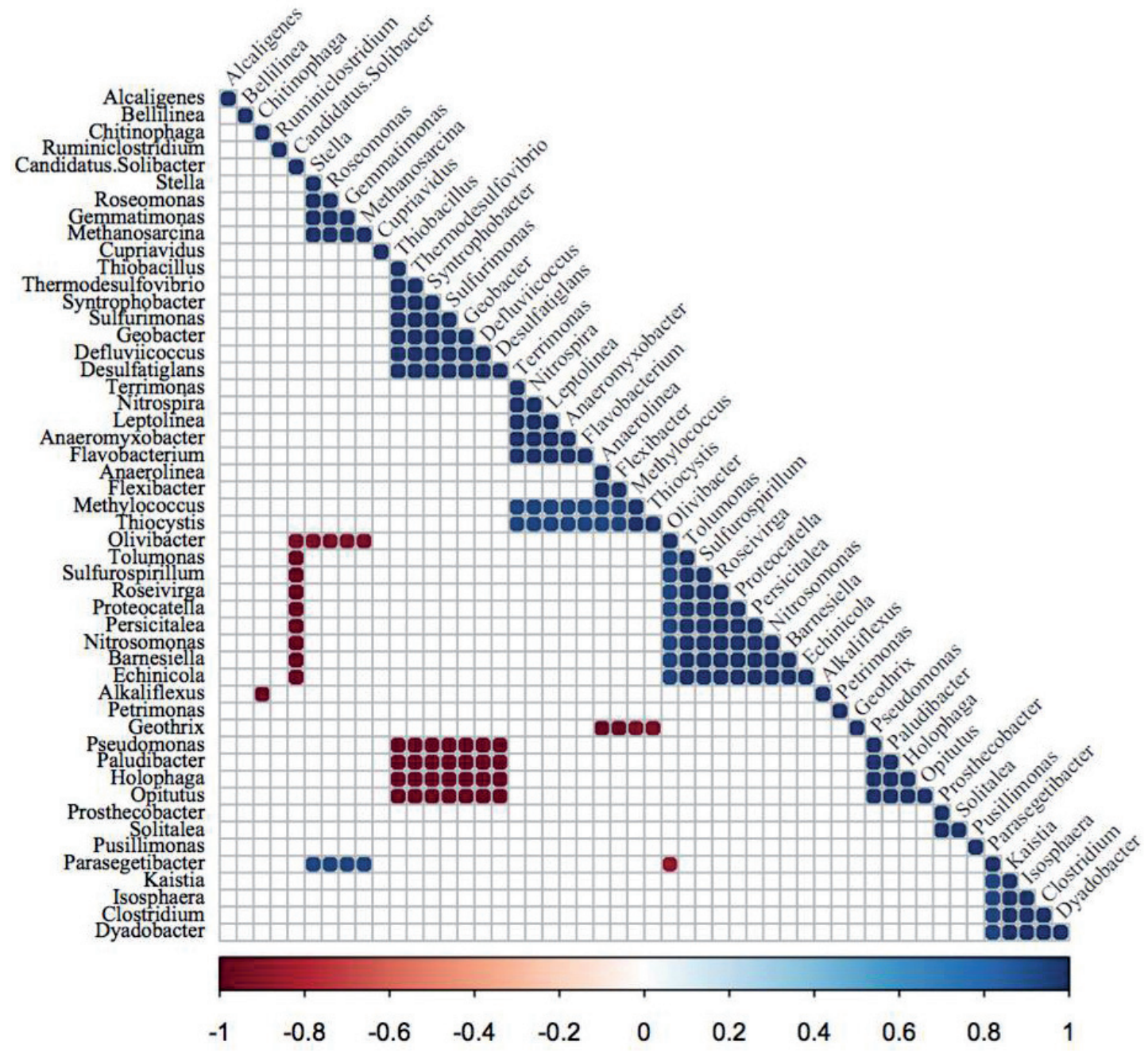

Fig. 6. Spearman rank correlation analysis of the 50 dominant microbial populations in sediment microbial fuel cells. Squares represent the correlation between two microbial communities was significant $(\mathrm{p}<0.01)$. Strong correlations are indicated by dark blue squares, whereas dark red squares indicate weak correlations. The scale bar colors denote the nature of the correlation with 1 showing a perfect positive correlation (dark blue) and -1 indicating perfect negative correlation (dark red) between two microbial populations.

to nitrite [33]. Paludibacter jiangxiensis is a strictly anaerobic, propionate-producing bacterium isolated from rice paddy field [34]. Study on the rhizosphere selection showed the Holophaga 16S rRNA gene number were more abundant in the leek rhizosphere than in bulk soil and the rhizospheres of grass and potato [35]. A cocultures study of Geobacter and Pseudoma aeruginosa suggested a transition from syntrophy to competition [36]. Anaerolinea and Syntrophobacter were found dominantly present in the anode of glucose fed MFC, suggesting syntrophic interaction of these fermentative bacteria with exoelectrogens [8]. Flexibacter showed positively correlated with most core bacteria, Blastocatella, Chloronema, Desulfobulbus, Geobacter, Leptolyngbya, Rivibacter, Spirochaeta, and Synechococcus in response to indica and japonica bar-transgenic rice paddy soils [37]. With a genome-scale metabolic model for Methylococcus capsulatus suggesting the reduced efficiency for the methane monooxygenase to the oxidation of methane [38]. Thiocystis is a purple sulfur bacterium capable of phototrophic growth with sulfide or sulfur as an electron donor under anoxic conditions [39]. Different soil sources in MFCs would yield divergent microbial communities [19, 40]. Soil nutrient and carbon availability has been shown to affect microbial communities, for example, in response to glucose amendment, the microbial communities changed towards to glucose utilization [41]. The microbial community dynamics also could be affected by MFC operation, and the bacteria Geobacter and Thermincola could be responsible for bioelectricity generation [42]. In a mixed community in MFCs, the microorganisms that would respire at the most negative anodic potential will displace other strains that cannot adapt to the more negative potential [43]. Alternatively, syntrophic interactions have previously been suggested in a study of anode biofilms from glucose-fed and acetatefed MFC [9]. To further investigate the microbial interaction, metatranscriptomics seems to be the best 
method to identify soil microorganisms and protein activity at the time of sampling for interpretation of the regulatory mechanism [44, 45]. Recently, efforts with enhanced electricity generation in paddy plant MFC and paddy-field MFC, the maximum power density could reach $40.3 \mathrm{mWm}^{-2}$ and $130 \mathrm{mWm}^{-2}$ respectively [46, 47], combined with an ultra-low-power energy harvester specially designed for MFCs which can extract energy even from extremely low-power, inexpensive, and single MFCs for the autonomous environmental sensing [48], suggesting a feasible environmental application for the MFCs.

\section{Conclusion}

This study shows that the presence of Geobacter and Geothrix is relative to power output and the microbial community of the anode-associated soil is in a dynamic syntrophic or competitive relationship. The electrochemical capability modulated by sediment MFCs would cause a change in the microbial community, and an ideal mixed community is likely to form for maximum or sustained power generation. Future studies will study the complex interactions among anode-associated microbes.

\section{Acknowledgements}

Authors would like to thank Mr. Cheng-Yu Lin for his hard work. Financial support was provided partly by grant ORD-104074 from Da-Yeh University to C.-H. L.

\section{Conflict of Interest}

The authors declare no conflict of interest.

\section{References}

1. LOVLEY D.R. Microbial fuel cells: novel microbial physiologies and engineering approaches. Curr Opin Biotechnol. 17 (3), 327, 2006.

2. SLATE A.J., WHITEHEAD K.A., BROWNSON D.A., BANKS C.E. Microbial fuel cells: An overview of current technology. Renewable and Sustaniable Energy Reviews. 101, 22, 2019.

3. BOND D.R., HOLMES D.E., TENDER L.M., LOVLEY D.R. Electrode-reducing microorganisms that harvest energy from marine sediments. Science. 295 (5554), 483, 2002.

4. GIRGUIS P.R., NIELSEN M.E., FIGUEROA I. Harnessing energy from marine productivity using bioelectrochemical systems. Curr Opin Biotechnol. 21 (3), 252, 2010.

5. SHI L., DONG H., REGUERA G., BEYENAL H., LU A., LIU J., YU H.Q., FREDRICKSON J.K. Extracellular electron transfer mechanisms between microorganisms and minerals. Nat Rev Microbiol. 14 (10), 6512, 2016.
6. CAO Y., MU H., LIU W., ZHANG R., GUO J., XIAN M., LIU, H. Electricigens in the anode of microbial fuel cells: pure cultures versus mixed communities. Microb Cell Fact. 18 (1), 39, 2019.

7. HOLMES D.E., BOND D.R., O'NEIL R.A., REIMERS C.E., TENDER L.R., LOVLEY D.R. Microbial communities associated with electrodes harvesting electricity from a variety of aquatic sediments. Microb Ecol. 48 (2), 178, 2004.

8. KOUZUMA A., KASAI T., NAKAGAWA G., YAMAMURO A., ABE T., WATANABE K. Comparative metagenomics of anode-associated microbiomes developed in rice paddy-field microbial fuel cells. PLoS One. 8 (11), e77443, 2013.

9. YAMAMURO A., KOUZUMA A., ABE T., WATANABE $\mathrm{K}$. Metagenomic analyses reveal the involvement of syntrophic consortia in methanol/electricity conversion in microbial fuel cells. PLoS One. 9 (5), e98425, 2014.

10. ZHANG H., CHEN X., BRAITHWAITE D., HE Z. Phylogenetic and metagenomic analyses of substratedependent bacterial temporal dynamics in microbial fuel cells. PLoS One. 9 (9), e107460, 2014.

11. ISHII S., SUZUK, S., NORDEN-KRICHMAR T.M., PHAN T., WANGER G., NEALSON K.H., SEKIGUCHI Y., GORBY Y.A., BRETSCHGER O. Microbial population and functional dynamics associated with surface potential and carbon metabolism. ISME J. 8 (5), 963, 2014.

12. ALTSCHUL S.F., GISH W., MILLER W., MYERS E.W., LIPMAN D.J. Basic local alignment search tool. J Mol Biol. 215 (3), 403, 1990.

13. HUSON D.H., BEIER S., FLADE I., GORSKA A., EL-HADIDI M., MITRA S., RUSCHEWEYH H.J., TAPPU R. MEGAN Community Edition - Interactive Exploration and Analysis of Large-Scale Microbiome Sequencing Data. PLoS Comput Biol. 12 (6), e1004957, 2016.

14. GU Z., EILS R., SCHLESNER M. Complex heatmaps reveal patterns and correlations in multidimensional genomic data. Bioinformatics. 32 (18), 2847, 2016.

15. R CORE TEAM R: A language and environment for statistical computing. R Foundation for Statistical Computing, Vienna, Austria. 2017; Available from: https:// www.R-project.org/.

16. SUZUKI K., TAKEMURA M., MIKI T., NONAKA M., HARADA N. Differences in Soil Bacterial Community Compositions in Paddy Fields under Organic and Conventional Farming Conditions. Microbes Environ. 34 (1), 108, 2019.

17. YATES M.D., KIELY P.D., CALL D.F., RISMANI-YAZDI H., BIBBY K., PECCIA J., REGAN J.M., LOGAN B.E. Convergent development of anodic bacterial communities in microbial fuel cells. ISME J. 6 (11), 2002, 2012.

18. TOCZYLOWSKA-MAMINSKA R., SZYMONA K., KROL P., GLINIEWICZ K., PIELECH-PRZYBYLSKA K., KLOCH M., AND LOGAN B.E. Evolving microbial communities in cellulose-fed microbial fuel cell. Energies. 11 (1), 12, 2018.

19. SONG N., JIANG H., YAN Z. Contrasting Effects of Sediment Microbial Fuel Cells (SMFCs) on the Degradation of Macrophyte Litter in Sediments from Different Areas of a Shallow Eutrophic Lake. applied sciences. 9 (18), 13, 2019.

20. ISHII S., SHIMOYAMA T., HOTTA Y., WATANABE $\mathrm{K}$. Characterization of a filamentous biofilm community established in a cellulose-fed microbial fuel cell. BMC Microbiol. 8 6, 2008. 
21. SASAKI D., SASAKI K., TSUGE Y., KONDO A. Less biomass and intracellular glutamate in anodic biofilms lead to efficient electricity generation by microbial fuel cells. Biotechnol Biofuels. 12 72, 2019.

22. BOND D.R., LOVLEY D.R. Evidence for involvement of an electron shuttle in electricity generation by Geothrix fermentans. Appl Environ Microbiol. 71 (4), 2186, 2005

23. MIYAHARA M., HASHIMOTO K., WATANABE K. Use of cassette-electrode microbial fuel cell for wastewater treatment. J Biosci Bioeng. 115 (2), 176, 2013.

24. SUZUKI D., LI Z., CUI X., ZHANG C., KATAYAMA, A. Desulfatiglans anilini comb. nov. within Desulfatiglans gen. nov., and description of a 4-chlorophenoldegrading sulfate-reducing bacterium, Desulfatiglans parachlorophenolica sp. nov. International Journal of Systematic and Evolutionary Microbiology. 64 6, 2014.

25. MUYZER G., STAMS A.J. The ecology and biotechnology of sulphate-reducing bacteria. Nat Rev Microbiol. 6 (6), 441, 2008.

26. VUILLEMIN A., HORN F., FRIESE A., WINKEL M., ALAWI M., WAGNER D., HENNY C., ORSI W.D., CROWE S.A., KALLMEYER J. Metabolic potential of microbial communities from ferruginous sediments. Environ Microbiol. 20 (12), 4297, 2018.

27. JORGENSEN B.B., FINDLAY A.J., PELLERIN A. The Biogeochemical Sulfur Cycle of Marine Sediments. Front Microbiol. 10 849, 2019.

28. HAN Y., PERNER M. The globally widespread genus Sulfurimonas: versatile energy metabolisms and adaptations to redox clines. Front Microbiol. 6 989, 2015.

29. AOYAGI T., KIMURA M., YAMADA N., NAVARRO R.R., ITOH H., OGATA A., SAKODA A., KATAYAMA Y., TAKASAKI M., HORI T. Dynamic transition of chemolithotrophic sulfur-oxidizing bacteria in response to amendment with nitrate in deposited marine sediments. Front Microbiol. 6 426, 2015.

30. ONETTO C.A., GRBIN P.R., MCILROY S.J., EALES K.L. Genomic insights into the metabolism of 'Candidatus Defluviicoccus seviourii', a member of Defluviicoccus cluster III abundant in industrial activated sludge. FEMS Microbiol Ecol. 95 (2), 2019.

31. FAN Y.Y., LI B.B., YANG Z.C., CHENG Y.Y., LIU D.F., YU H.Q. Abundance and diversity of iron reducing bacteria communities in the sediments of a heavily polluted freshwater lake. Appl Microbiol Biotechnol. 102 (24), 10791, 2018.

32. GAN Y., QIU Q., LIU P., RUI J., LU Y. Syntrophic oxidation of propionate in rice field soil at 15 and 30 degrees $\mathrm{C}$ under methanogenic conditions. Appl Environ Microbiol. 78 (14), 4923, 2012.

33. CHIN K.J., LIESACK W., JANSSEN P.H. Opitutus terrae gen. nov., sp. nov., to accommodate novel strains of the division 'Verrucomicrobia' isolated from rice paddy soil. Int J Syst Evol Microbiol. 51 (Pt 6), 1965, 2001.

34. QIU Y.L., KUANG X.Z., SHI X.S., YUAN X.Z., GUO R.B. Paludibacter jiangxiensis sp. nov., a strictly anaerobic, propionate-producing bacterium isolated from rice paddy field. Arch Microbiol. 196 (3), 149, 2014.

35. NUNES DA ROCHA U., PLUGGE C.M., GEORGE I., VAN ELSAS J.D., VAN OVERBEEK L.S. The rhizosphere selects for particular groups of acidobacteria and verrucomicrobia. PLoS One. 8 (12), e82443, 2013.
36. SEMENEC L., VERGARA I.A., LALOO A.E., PETROVSKI S., BOND P.L., FRANKS A.E. Adaptive Evolution of Geobacter sulfurreducens in Coculture with Pseudomonas aeruginosa. mBio. 11 (2), 2020.

37. HE M., ZHANG J., SHEN L., XU L., LUO W., LI D., ZHAI N., ZHAO J., LONG Y., PEI X., YUAN Q. Highthroughput sequencing analysis of microbial community diversity in response to indica and japonica bar-transgenic rice paddy soils. PLoS One. 14 (9), e0222191, 2019.

38. LIEVEN C., PETERSEN L.A.H., JORGENSEN S.B., GERNAEY K.V., HERRGARD M.J., SONNENSCHEIN N. A Genome-Scale Metabolic Model for Methylococcus capsulatus (Bath) Suggests Reduced Efficiency Electron Transfer to the Particulate Methane Monooxygenase. Front Microbiol. 9 2947, 2018.

39. PEDUZZI S., WELSH A., DEMARTA A., DECRISTOPHORIS P., PEDUZZI R., HAHN D., TONOLLA M. Thiocystis chemoclinalis sp. nov. and Thiocystis cadagnonensis sp. nov., motile purple sulfur bacteria isolated from the chemocline of a meromictic lake. Int J Syst Evol Microbiol. 61 (Pt 7), 1682, 2011.

40. YANG J., CHENG S. Effects of Using Anode Biofilm and Cathode Biofilm Bacteria as Inoculum on the Startup, Electricity Generation, and Microbial Community of Air-Cathode Single-Chamber Microbial Fuel Cells. Pol. J. Environ. Stud. 28 (2), 8, 2019.

41. ARCAND M.M., LEVY-BOOTH D.J., HELGASON B.L. Resource Legacies of Organic and Conventional Management Differentiate Soil Microbial Carbon Use. Front Microbiol. 8 2293, 2017.

42. LI X., LI Y., ZHANG X., ZHAO X., CHEN X., LI Y. The metolachlor degradation kinetics and bacterial community evolution in the soil bioelectrochemical remediation. Chemosphere. 248 125915, 2020.

43. LOGAN B.E. Exoelectrogenic bacteria that power microbial fuel cells. Nat Rev Microbiol. 7 (5), 375, 2009.

44. ROMERO-OLIVARES A.L., MELENDREZCARBALLO G., LAGO-LESTON A., TRESEDER K.K. Soil Metatranscriptomes Under Long-Term Experimental Warming and Drying: Fungi Allocate Resources to Cell Metabolic Maintenance Rather Than Decay. Front Microbiol. 10 1914, 2019.

45. SHARMA P.K., SHARMA V., SHARMA S., BHATIA, G., SINGH K., SHARMA R. Comparative metatranscriptome analysis revealed broad response of microbial communities in two soil types, agriculture versus organic soil. J Genet Eng Biotechnol. 17 (1), 6, 2019.

46. OMINE K., C.S.D., SIVASANKAR V. Current Advances in Paddy Plant Microbial Fuel Cells. Microbial Fuel Cell Technology for Bioelectricity, ed. M.P. Sivasankar V., Omine K. 2018: Springer, Cham.

47. MATSUMOTO A., NAGOYA M., TSUCHIYA M., SUGA K., INOHANA Y., HIROSE A., YAMADA S., HIRANO S., ITO Y., TANAKA S., KOUZUMA A., WATANABE $\mathrm{K}$. Enhanced electricity generation in rice paddy-field microbial fuel cells supplemented with iron powders. Bioelectrochemistry. 136 107625, 2020.

48. YAMASHITA T., HAYASHI T., IWASAKI H., AWATSU M., YOKOYAMA H. Ultra-low-power energy harvester for microbial fuel cells and its application to environmental sensing and long-range wireless data transmission. Journal of Power Sources. 430 11, 2019. 